\title{
WaLIDD score, a new tool to diagnose dysmenorrhea and predict medical leave in university students
}

This article was published in the following Dove Press journal: International Journal of Women's Health

\author{
Aníbal A Teherán' \\ Luis Gabriel Piñeros ${ }^{2}$ \\ Fabián Pulido ${ }^{3}$ \\ María Camila Mejía \\ Guatibonza' \\ 'Research Group COMPLEXUS, \\ ${ }^{2}$ Research Group GIFVTA, Fundación \\ Universitaria Juan N Corpas, \\ ${ }^{3}$ University Hospital San José of \\ Bogotá, Bogotá, Colombia
}

Background: Dysmenorrhea is a frequent and misdiagnosed symptom affecting the quality of life in young women. A working ability, location, intensity, days of pain, dysmenorrhea (WaLIDD) score was designed to diagnose dysmenorrhea and to predict medical leave.

Methods: This cross-sectional design included young medical students, who completed a selfadministered questionnaire that contained the verbal rating score (VRS; pain and drug subscales) and WaLIDD scales. The correlation between scales was established through Spearman test. The area under the receiver operating characteristic (ROC) curve, sensitivity, specificity, and likelihood ratio ( $\mathrm{LR}+/-$ ) were evaluated to diagnose students availing medical leave due to dysmenorrhea; moreover, to predict medical leave in students with dysmenorrhea, a binary logistic regression was performed.

Results: In all, 585 students, with a mean age of 21 years and menarche at 12 years, participated. Most of them had regular cycles, 5 days of menstrual blood flow and 1-2 days of lower abdominal pain. The WaLIDD scale presented an adequate internal consistency and strong correlation with VRS subscales. With a cutoff of $>6$ for WaLIDD and 2 for VRS subscales (drug subscale and pain subscale) to identify students with dysmenorrhea, these scales presented an area under the curve (AUC) ROC of 0.82, 0.62, and 0.67 , respectively. To identify students taking medical leave due to dysmenorrhea, WaLIDD (cutoff $>9$ ) and VRS subscales (cutoff $>2$ ) presented an AUC ROC of $0.97,0.68$, and 0.81 ; moreover, the WaLIDD scale showed a good LR +14.2 (95\% CI, 13.5-14.9), LR -0.00 (95\% CI, undefined), and predictive risk (OR 5.38; 95\% CI, 1.78-16.2). Conclusion: This research allowed a comparison between two multidimensional scales regarding their capabilities, one previously validated and a new one, to discriminate among the general population of medical students, among those with dysmenorrhea or those availing medical leave secondary to dysmenorrhea. WaLIDD score showed a larger effect size than the pain and drug score in the students. In addition, this study demonstrated the ability to predict this combination of events.

Keywords: dysmenorrhea, sick leave, diagnosis, medical students, clinical decision making

\section{Background}

Dysmenorrhea is a symptom that relates to several diagnosis of pelvic pain; it is manifested prior to the menstrual period and occasionally extends $\geq 72$ hours after its completion. Dysmenorrhea appears up to 6-12 months after menarche, affecting primarily young women, often those in university or occupational activity. During this stage of life, it is known as primary dysmenorrhea (PD) and is usually due to physiological causes, which have been linked to nutritional disorders, menstrual cycle irregularities, menarche before the age of 12, excessive menstruation, and other factors
Correspondence: María Camila Mejía Guatibonza

Research Group COMPLEXUS, Fundación Universitaria Juan $\mathrm{N}$ Corpas, Carrera II Number I59 A-6I, Bogotá, IIII, Colombia

Tel +57 6622222 ext 250

Email maria-mejia@juanncorpas.edu.co 
that characterize the university population between 20 and 25 years, such as nulliparity, stress, depression, smoking, and lack of social support. ${ }^{1-7}$

Worldwide, the prevalence of dysmenorrhea was estimated to be between $16 \%$ and $91 \%$. Two Colombian research studies have determined the prevalence to be between $63 \%$ and $73 \% .^{7-9}$

Absenteeism from academic and work activity is a negative consequence of dysmenorrhea and has been consistent with investigations that have addressed this problem in teenagers and young adults. During the days of menstrual bleeding, at least one out of three young women had to be absent due to the intensity of the pain or expressed their limitation to do daily activities. ${ }^{10-14}$

The diagnosis of dysmenorrhea is clinical. Some investigations identify cases using numerical scales of pain, which at the same time serve to classify intensity; others include characteristics such as intensity of pain, limitation to perform daily activities, or the requirement of analgesic management (local or systemic) among others. ${ }^{15,16}$

Nowadays, there is no uniformity in the diagnostic process and in the use of standard surveys with adequate measurements of validation and construction, that permit classification of the severity of dysmenorrhea. This may explain the variability in prevalence, inaccuracies in associations established with absenteeism, or errors in the diagnostic approach to patients with pelvic pain.

The verbal rating score (VRS) is one of the most used in clinical research on dysmenorrhea and pelvic pain, but its lack of information regarding construct validation has led to unfavorable criticism about its usefulness in clinical scenarios. We hypothesized that when comparing pain and drug score with other characteristics, it could lead us to predict medical leave. The objective of this research is to design and implement an instrument which, for the general population, allows the identification of women with dysmenorrhea, and among them, those with a high risk of availing medical leave. ${ }^{16-18}$

\section{Methods}

\section{Design, setting, and selection of participants}

A cross-sectional study was carried out in undergraduate students over 18 years old at Fundación Universitaria Juan N Corpas (FUJNC), who wished to complete the questionnaire, between November 2014 and February 2015.

\section{Data collection and database description}

A scale-type survey (working ability, location, intensity, days of pain, dysmenorrhea [WaLIDD] score) was designed, which integrated features of dysmenorrhea such as: 1) number of anatomical pain locations (no part of the body, lower abdomen, lumbar region, lower limbs, inguinal region), 2) Wong-Baker pain range (does not hurt, hurts a little, hurts a little more, hurts even more, hurts a lot, hurts a lot more), ${ }^{19} 3$ ) number of days of pain during menstruation ( 0 , $1-2,3-4, \geq 5$ ), and 4) frequency of disabling pain to perform their activities (never, almost never, almost always, always). Each tool's variable provided a specific score between 0 and 3 , and the final score ranged from 0 to 12 points (Table 1 ).

The WaLIDD instrument was within an anonymous questionnaire that included all the variables evaluated in this research; in addition, it included information regarding age, menarche, characteristics of the menstrual cycle, type and number of nonsurgical treatments used to manage dysmenorrhea, number of days of medical leave due to dysmenorrhea 3 months prior to the survey, and the items "pain and drug score" contained in the VRS instrument. This questionnaire was submitted for a validation of content carried out by a psychologist and a gynecologist, external to the research (Supplementary material http://www.juanncorpas.edu.co/ investigacion/documentos-de-interes/).

A pilot test was carried out with 20 adult women (not included in the later analyses) with the objective of identifying limitations in the comprehension of the items of the questionnaire and measuring the correlation between 1) two independent scores obtained from a previously validated instrument (VRS), designed to measure the intensity of dysmenorrhea, and 2 ) the score obtained with the WaLIDD survey. ${ }^{18}$

A case of dysmenorrhea was identified by fulfillment of the following five criteria: 1) hypogastrium pain during menstruation, 2) irradiation to the lower back, lower limbs, or inguinal region, 3 ) intensity $\geq 2$ on the Wong-Baker scale during the last 3 months, 4) inability to perform daily activity, and 5) the need for medical management or self-medication to control pain. ${ }^{1,3,4,10}$

Table I WaLIDD score variables

\begin{tabular}{|c|c|c|c|}
\hline $\begin{array}{l}\text { Working } \\
\text { ability }\end{array}$ & Location & $\begin{array}{l}\text { Intensity } \\
\text { (Wong-Baker) }\end{array}$ & $\begin{array}{l}\text { Days } \\
\text { of pain }\end{array}$ \\
\hline $0:$ None & 0: None & 0: Does not hurt & $0: 0$ \\
\hline I: Almost never & I: I site & I: Hurts a little bit & I: I-2 \\
\hline 2: Almost always & 2: $2-3$ sites & $\begin{array}{l}\text { 2: Hurts a little more - } \\
\text { hurts even more }\end{array}$ & $2: 3-4$ \\
\hline 3: Always & 3: 4 sites & $\begin{array}{l}\text { 3: Hurts a whole lot - } \\
\text { hurts worst }\end{array}$ & $3: \geq 5$ \\
\hline
\end{tabular}

Notes: Score: 0 without dysmenorrhea, 1-4 mild dysmenorrhea, 5-7 moderate dysmenorrhea, 8-12 severe dysmenorrhea. Wong-Baker scale was reclassified to adjust a four-level scale.

Abbreviation: WaLIDD, working ability, location, intensity, days of pain, dysmenorrhea. 


\section{Outcome measure}

The primary outcome was determination of the operating capabilities of the WaLIDD score to discriminate students with dysmenorrhea in the university population and the prediction of medical leave among these students.

\section{Statistical analysis}

Statistical packages, Epi-Info ${ }^{\circledR}$ version 3.5.4 (Center for Disease Control and Prevention, Atlanta, GA, USA), Minitab ${ }^{\circledR}$ version 17 (Minitab Inc, State College, PA, USA), and SPSS ${ }^{\circledR}$ version 22 (IBM Corporation, Armonk, NY, USA), were used to graph and analyze the data. The results were expressed in proportions and mean (SD). Shapiro-Wilk's test was used to reject normality; the correlation grade (Spearman-Rho) between scores of dysmenorrhea (VRS and WaLIDD scale) or other numerical variables was determined. Chi-square test was used to compare categorical variables, and the non-paired $t$-test was used for two independent quantitative variables. Nonparametric statistics was used to compare medians. A $p$-value $<0.05$ was considered significant.

Sensitivity, specificity, positive/negative predictive value, area under the curve (AUC), likelihood ratio LR (+), LR (-), and the optimal cutoff points of the drug, pain, and WaLIDD scales were determined to identify students with dysmenorrhea $(1 / 0)$, availing medical leave $(1 / 0)$, or with both conditions (1/0). The effect size (Cohen's d) was compared between the three scales, according to influential characteristics in measuring the degree of dysmenorrhea (Table S1).

The scores of the three dysmenorrhea scales were compared in the general population of students and in those classified or not classified, with dysmenorrhea, medical leave, or both conditions. The relationship (OR, 95\% CI) between characteristics of the dysmenorrhea scales and the risk of medical leave was determined using a $2 \times 2$ table. A logistic regression model was implemented to predict the risk of identifying students with dysmenorrhea and medical leave $(y)$ using the scores obtained in any of the three dysmenorrhea scales $(x 1, x 2, x 3)$.

\section{Sample size}

A sample of 191 students was selected, using the statistical package Epidat version ${ }^{\circledR} 3.1$ (Dirección Xeral de Saúde Pública [Xunta de Galicia], A Coruña, Spain). The parameters were sensitivity $90 \%$, prevalence of dysmenorrhea $73 \%$, precision $5 \%$, and confidence $95 \% .{ }^{8}$ This sample size was chosen from 1,645 undergraduates, $60.4 \%$ female (994), that were undergoing their degree program up to the 10th semester.

\section{Ethical considerations}

This research was classified as one without risk, according to resolution $008430 / 1993$ of Colombia; information was collected from volunteers and the completed questionnaire guaranteed complete anonymity. Given the ethical classification of the study and its protocol, it only required approval by the Research and Ethics Committee at FUJNC which was obtained. The students completed the survey voluntarily.

\section{Results}

In all, 585 students were included, with a mean age of 21 years and menarche at 12 years on average; the latter was precocious in one out of four; most had regular cycles and a 5-day average time span of menstrual bleeding (Table S2).

The students reported localized pain in the hypogastrium $(494 / 585,84.4 \%)$, with a time span of $1-2$ days $(417 / 585$, $71.3 \%$ ) and moderate intensity, which according to the scale used ranged from $28 \%$ (167/585, drug scale) to $54 \%$ (3e16/585, WaLIDD scale); expressed limitation to perform an activity $(128 / 585,21.8 \%)$; and with a high frequency they needed analgesics at least once a day $(184 / 585,31.5 \%)$.

\section{Frequency and features of students classified with dysmenorrhea}

Once the case definition was implemented, the overall frequency of dysmenorrhea was found to be $20.5 \%$ (95\% CI, 17.2-23.9) and for those identified with early menarche ( $<11$ years old), 33.3\% (40/120; 95\% CI, 24.5-42.2) (data not shown).

Moderate intensity of pain was the most frequent category in students classified with dysmenorrhea; using drug, pain, and WaLIDD scales, proportions of students with moderate intensity pain were $46.6 \%(56 / 120), 68.3 \%(82 / 120)$, and $60.8 \%$ (73/120), respectively. Students with dysmenorrhea had between 3 and 4 days of pain, were classified 1 or 2 in their capacity to perform work activities, and needed to ingest analgesics for 2 days (drug score), compared with those that did not meet the case definition for dysmenorrhea (Table 2).

Seventy-five percent reported the use of some type of therapeutic method to manage pain; the median (p25-p75) of the number of methods used by students with dysmenorrhea was $2(2-3)$ and without dysmenorrhea was $1(0-2)$ $(p<0.001)$. Among those classified with dysmenorrhea, use of analgesics/anti-inflammatories (101/120, 84.2\%), followed by relaxation/pillow/local heat use (77/120, 64.2\%), and infusion/aromatic use $(66 / 120,55.0 \%)$ were the most commonly adopted therapeutic methods (data not shown).

\section{Characteristics of VRS and WaLIDD score}

The scores obtained with the three surveys presented asymmetric distributions. The standardized score of the pain score was the highest; this score classified those university female 
Table 2 Features of dysmenorrhea in university students

\begin{tabular}{|c|c|c|c|c|}
\hline $\begin{array}{l}\text { Features } \\
\text { score }\end{array}$ & $\begin{array}{l}\text { Dysmenorrhea } \\
n=\mid 20(20.5 \%)\end{array}$ & $\begin{array}{l}\text { Non-dysmenorrhea } \\
n=465 \text { (79.5\%) }\end{array}$ & $\begin{array}{l}\text { Total } \\
n=585\end{array}$ & $p$-value \\
\hline \multicolumn{5}{|c|}{ WaLIDD score } \\
\hline \multicolumn{5}{|c|}{ Location, n (\%) } \\
\hline Lumbar & $86(71.7)$ & 117 (25.2) & $203(34.7)$ & 0.000 \\
\hline Thighs & $4 I(34.2)$ & $40(6.6)$ & 81 (I3.8) & 0.000 \\
\hline Inguinal & $25(20.8)$ & $22(4.7)$ & $47(8.03)$ & 0.000 \\
\hline \multicolumn{5}{|c|}{ Wong-Baker, n (\%) } \\
\hline I & $8(6.7)$ & $87(18.7)$ & $95(16.2)$ & 0.023 \\
\hline 2 & $45(37.5)$ & 191 (4I.I) & $236(40.3)$ & 0.543 \\
\hline 3 & $67(55.8)$ & $142(30.5)$ & $209(35.7)$ & 0.000 \\
\hline \multicolumn{5}{|c|}{ Days of pain, n (\%) } \\
\hline 0 & I (2.04) & $49(30.5)$ & $50(8.54)$ & 0.000 \\
\hline 1 & $78(65.0)$ & $339(72.9)$ & $417(7 \mid .2)$ & 0.111 \\
\hline 2 & $35(29.2)$ & $65(14.0)$ & $100(17.1)$ & 0.000 \\
\hline 3 & $6(5.0)$ & $12(2.6)$ & $18(3.08)$ & 0.283 \\
\hline \multicolumn{5}{|c|}{ Working ability, n (\%) } \\
\hline 1 & $80(66.7)$ & $210(45.2)$ & $290(49.5)$ & 0.000 \\
\hline 2 & $35(29.2)$ & $73(15.7)$ & $108(18.4)$ & 0.001 \\
\hline 3 & $5(4.2)$ & $15(3.2)$ & $20(3.4)$ & 0.822 \\
\hline \multicolumn{5}{|c|}{ Verbal rating score } \\
\hline \multicolumn{5}{|c|}{ Pain score, n (\%) } \\
\hline 0 & $16(13.3)$ & $156(33.6)$ & I 72 (29.4) & 0.000 \\
\hline I & $19(18.7)$ & $76(14.8)$ & $95(16.2)$ & 0.997 \\
\hline 2 & $82(68.3)$ & $230(47.9)$ & $312(53.3)$ & 0.000 \\
\hline 3 & $3(2.5)$ & $3(0.6)$ & $6(1.0)$ & 0.197 \\
\hline \multicolumn{5}{|c|}{ Drug score, $\mathrm{n}(\%)$} \\
\hline 0 & II (9.2) & $166(35.7)$ & $177(30.2)$ & 0.000 \\
\hline 1 & $36(30.0)$ & | 48 (3|.8) & I84 (3I.4) & 0.783 \\
\hline 2 & $56(46.7)$ & III (23.9) & $167(28.5)$ & 0.000 \\
\hline 3 & $17(14.2)$ & $40(8.6)$ & $57(9.7)$ & 0.096 \\
\hline
\end{tabular}

Note: Lower abdominal location, Wong-Baker, and work ability items were not analyzed because the first was used as part of the definition of dysmenorrhea cases and other cases were discarded.

Abbreviation: WaLIDD, working ability, location, intensity, days of pain, dysmenorrhea.

students with mild and severe pain, with less frequency. In turn, these classifications were identified more frequently when assessing pain with the drug and WaLIDD score scales (Table 3).

WaLIDD score showed an acceptable internal consistency (Cronbach's alpha $=0.723$ ); VRS consists of two different scores: pain and drug. There is a strong correlation of WaLIDD with the pain score $(\mathrm{Rho}=0.736)$ and a very strong correlation with the drug score $(\mathrm{Rho}=0.833)$ and the sum of the pain and drug score (Rho $=0.840)$ (Table S3).

Table 3 and Figure 1 show the operating capacities of the three scales to diagnose dysmenorrhea. Starting at 6 points, WaLIDD score demonstrated high capability to discriminate among students with or without dysmenorrhea, with a high predictive value to discard the event in those with scores below the calculated cutoff point, compared to the subscales of the VRS. Also, Figure 2 shows that all scales, VRS (pain and drug subscale) and WaLIDD scale, had an AUC of $>0.6$ to discriminate between students with or without dysmenorrhea. The AUC estimated with the WaLIDD scale was better than with the subscales of VRS, and the lowest AUCs were obtained with pain's subscale.

When comparing the size of the effect of some pain measurement variables between the three scales, the WaLIDD score showed a larger effect size than the pain and drug score in students with the following conditions: dysmenorrhea, disability + dysmenorrhea, bleeding over 5 days, intensity in the last 3 months (WaLIDD $\geq 1$ and Wong-Baker $\geq$ hurts a little), more than one location of pain, and $\geq 1$ day of pain (Table $\mathrm{S} 1$ ).

\section{Medical leave and dysmenorrhea scores}

One out of five students reported that they took medical leave; the frequency of students classified with dysmenorrhea and requiring medical leave in the last 3 months was $2.5 \%(3 / 120$, 95\% CI, 0.5-7.1). No differences were identified between 
Table 3 Comparison of dysmenorrhea scores

\begin{tabular}{|c|c|c|c|}
\hline \multirow[t]{2}{*}{ Properties } & \multicolumn{2}{|l|}{ VRS } & \multirow{2}{*}{$\begin{array}{l}\text { WaLIDD score } \\
(n=585)\end{array}$} \\
\hline & Pain score $(n=585)$ & Drug score $(n=585)$ & \\
\hline Interval & $0-3$ & $0-3$ & $0-12$ \\
\hline $\mathrm{SWT}^{\mathrm{a}}$ (statistic) & $0.737 * * *$ & $0.86 I^{* * *}$ & $0.972 * * *$ \\
\hline Mean & 1.26 & 1.18 & 5.48 \\
\hline SD & 0.89 & 0.97 & 2.12 \\
\hline Median ${ }^{\mathrm{b}, * * *}$ & 2 & I & 5 \\
\hline Quartiles (p25-p75) & $0-2$ & $0-2$ & $4-7$ \\
\hline Standardized median ${ }^{c}(\%)$ & 66.7 & 33.3 & 33.3 \\
\hline Scoring minimum, n (\%) & $172(29.4)$ & $177(30.3)$ & $5(0.85)$ \\
\hline Scoring maximum, n (\%) & $6(1.0)$ & $57(9.7)$ & $0(0.0)$ \\
\hline \multicolumn{4}{|l|}{ Level of pain, ${ }^{d} n(\%)$} \\
\hline None*** & $172(29.4)$ & $177(30.3)$ & $5(0.85)$ \\
\hline Mild*** & $95(16.2)$ & $184(3 \mid .5)$ & $156(26.7)$ \\
\hline Moderate*** & $312(53.3)$ & $167(28.6)$ & $319(54.4)$ \\
\hline Severe*** & $6(1.0)$ & $57(9.7)$ & $106(18.1)$ \\
\hline \multicolumn{4}{|c|}{ Diagnostic properties $(95 \% \mathrm{Cl})$} \\
\hline Cutoffe & 2 & 2 & 6 \\
\hline Sensitivity, \% & $71.3(62.2-78.2)$ & $60.8(51.9-69.1)$ & $93.3(87.1-96.7)$ \\
\hline Specificity, \% & $49.9(45.4-54.4)$ & $67.5(63.1-7 \mid .6)$ & $61.9(57.4-66.2)$ \\
\hline PPV, \% & $26.7(22.2-31.9)$ & $32.6(26.8-39.0)$ & $38.8(33.3-44.5)$ \\
\hline NPV, \% & $86.3(82.3-90.4)$ & $87.0(83.1-90.1)$ & $97.3(94.8-98.6)$ \\
\hline $\mathrm{LR}+$ & $1.41(1.39-1.44)$ & $1.87(1.82-1.93)$ & $2.45(2.42-2.48)$ \\
\hline LR - & $0.58(0.55-0.62)$ & $0.58(0.56-0.6 \mathrm{I})$ & $0.11(0.08-0.14)$ \\
\hline
\end{tabular}

Notes: ${ }^{\mathrm{S} S W T}$. ${ }^{\mathrm{b} K r u s k a l l-W a l l i s ~ t e s t . ~ ' E x p r e s s e d ~ o v e r ~ a ~ r a n g e ~ f r o m ~} 0$ to 100 by the following formula: standardized value $=$ raw score for the scale/maximal possible raw score $\times 100$. ${ }^{\mathrm{d}} \mathrm{Chi}$ Cuadrado test $\left(\chi^{2}\right)$. ${ }^{\mathrm{e}}$ The cutoffs were automatically obtained, using the statistical software SPSS version $22 . * * * p<0.00 \mathrm{I}$.

Abbreviations: LR, likelihood ratio; NPV, negative predictive value; PPV, positive predictive value; SWT, Shapiro Wilk test; VRS, verbal rating score; WaLIDD, working ability, location, intensity, days of pain, dysmenorrhea.

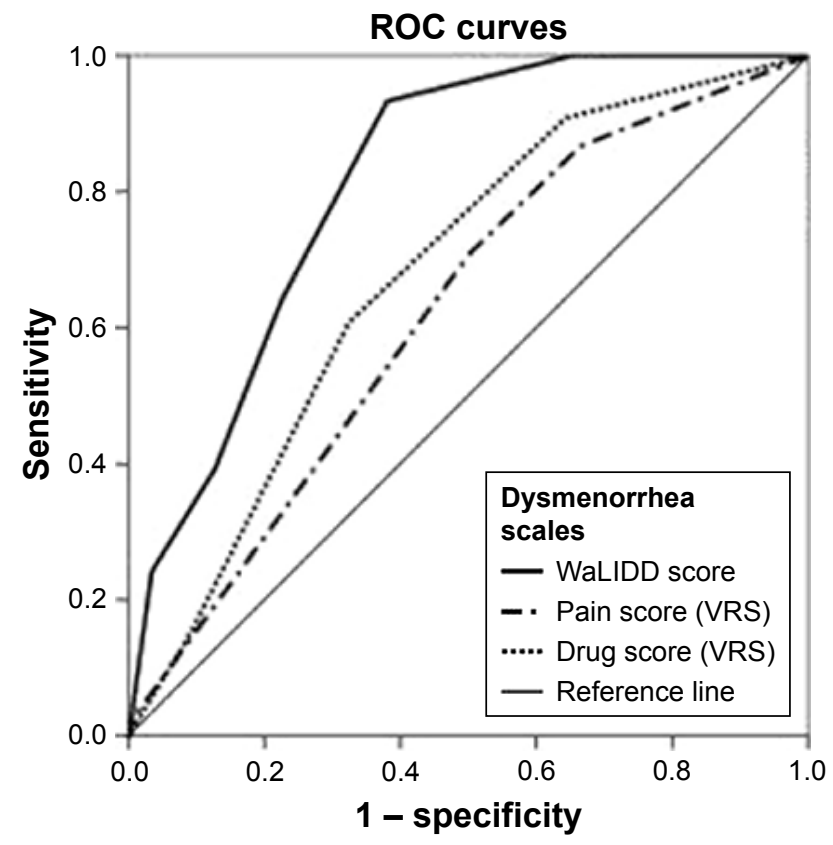

Figure I ROC curves of VRS sub-scores and WaLIDD score in dysmenorrhea cases.

Notes: WaLIDD score AUC 0.817 (95\% Cl, 0.78I-0.852); pain score AUC 0.623 (95\% Cl, 0.570-0.623); drug score AUC 0.678 (95\% Cl, 0.628-0.727).

Abbreviations: AUC, area under the curve; ROC, receiver operating characteristic; VRS, verbal rating score; WaLIDD, working ability, location, intensity, days of pain, dysmenorrhea. those with or without medical leave, in relation to some characteristics of the menstrual cycle (Table S2).

With the three scales, a higher score was found in students classified with dysmenorrhea, with a history of medical leave, or both, when compared with the target population (Figure 2) and with students without these characteristics (data not shown).

Table S4 shows the relationship between past history of medical leave and subcategories of the dysmenorrhea scales. Four subcategories of the WaLIDD score exhibited similarities: 1) it hurts a whole lot - hurts worst of WongBaker (WaLIDD: intensity 3) (OR 1.74; 95\% CI, 1.18-2.56), 2 ) $\geq 5$ days of pain (WaLIDD: duration 3 ) (OR 2.63; 95\% CI, 1.02-6.81), 3) almost always (WaLIDD: work ability 2) (OR $1.79 ; 95 \%$ CI, 1.13-2.82), and 4) always presents limitations for performing work activities (WaLIDD: work ability 3) (OR 3.34; 95\% CI, 1.36-8.26). In regard to VRS, similarity was observed in the need to use $\geq 3$ analgesics (pain score: level 3) (OR 2.58; 95\% CI, 1.46-4.54).

The operating capabilities to discriminate between students classified with dysmenorrhea who required medical leave and those who only manifested dysmenorrhea of the 


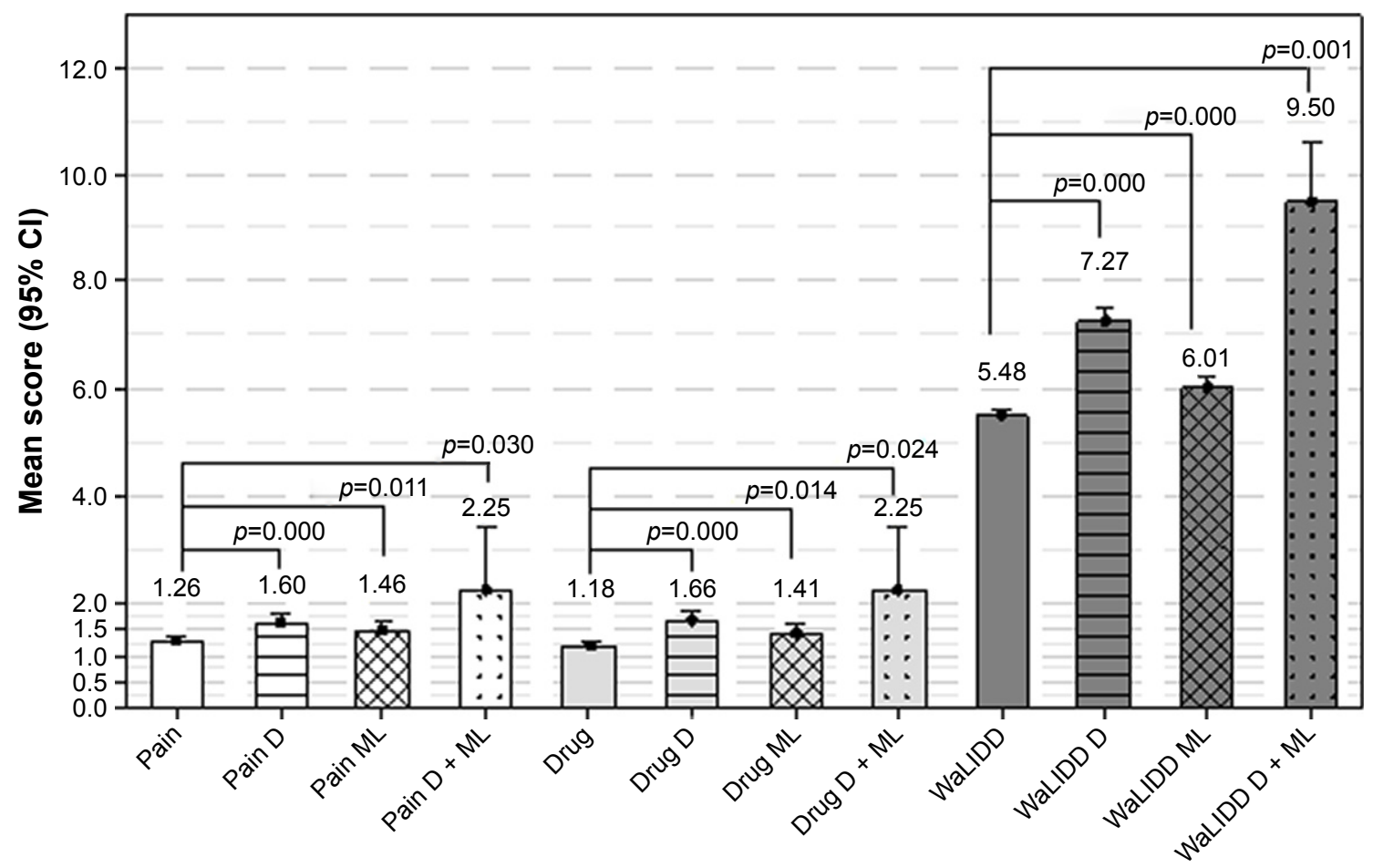

Figure 2 Dysmenorrhea scores in a general population of university students with dysmenorrhea, medical leave, or both features.

Notes: The pain and drug scales, both with 0-3 points interval, and working ability, location, intensity, days of pain, dysmenorrhea (WaLIDD) scale with 0-I2 points interval, are represented in all university students (general population), with dysmenorrhea (D), with medical leave (ML), or both features (D + ML). Bars without lines or dots represent scores in the general population (pain, drug, WaLIDD); horizontal lines represent students classified with dysmenorrhea (pain D, drug D, WaLIDD D); crossed lines represent students with medical leave (pain ML, drug ML, WaLIDD ML); and dots represent students with dysmenorrhea and medical leave (pain D + ML, drug $D+M L$, WaLIDD D + ML).

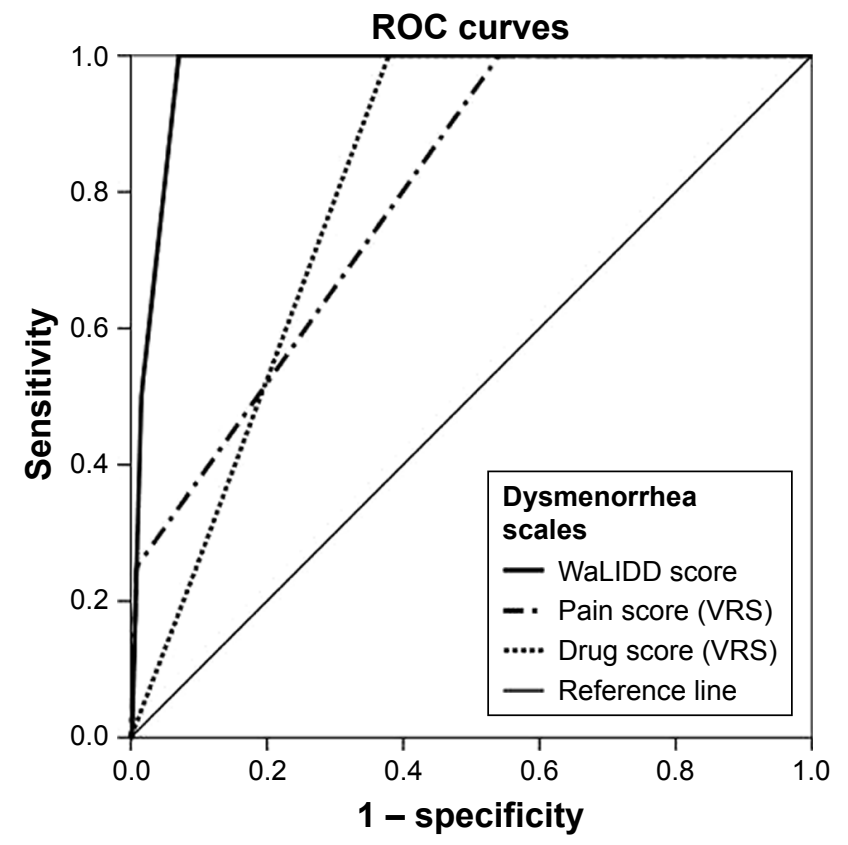

Figure 3 ROC curves of VRS sub-scores and WaLIDD score in dysmenorrhea cases with medical leave.

Notes: WaLIDD score AUC 0.974 (95\% Cl, 0.95I-0.997); pain score AUC 0.793 (95\% Cl, 0.6I8-0.968); and drug score AUC 0.810 (95\% Cl, 0.700-0.920).

Abbreviations: AUC, area under the curve; ROC, receiver operating characteristic; VRS, verbal rating score; WaLIDD, working ability, location, intensity, days of pain, dysmenorrhea.
WaLIDD score with a cutoff point of $\geq 9$ were sensitivity $100 \%$, specificity $92.9 \%$, positive predictive value (PPV) $78 \%$, negative predictive value (NPV) $100 \%$, LR +14.2 (95\% CI, 13.5-14.9), LR -0.00 (95\% CI, undefined); pain scores with a cutoff point of $\geq 2$ were sensitivity $100 \%$, specificity 46\%, PPV 31.6\%, NPV 100\%, LR +1.85 (95\% CI, 1.84-1.86), and LR -0.00 (95\% CI, undefined); drug scores with a cutoff point of $\geq 2$ were sensitivity $100 \%$, specificity $62.1 \%$, PPV $39.8 \%$, NPV $100 \%$, LR +2.64 (95\% CI, 2.62-2.67), and LR -0.00 (95\% CI, undefined) (Figure 3).

A binary logistic regression with forward selection, which included the intercept and used as independent variables the scores obtained in the three scales, including the model variables with $p<0.05$ and excluding those with $p>0.2$, was designed to predict the risk of identifying students with dysmenorrhea and medical leave. For the WaLIDD score, OR 5.38 (1.78-16.2), $\beta=1.682, p=0.003$ were determined; the model was adjusted (Hosmer-Lemeshow 0.995 ) and its global predictive capacity was $99.1 \%$; the other two variables were excluded from the model (pain and drug score). 


\section{Discussion}

This research allowed a comparison between two multidimensional scales regarding their capabilities, one previously validated and another new one, to discriminate among the general population of medical students, those with dysmenorrhea or medical leave secondary to dysmenorrhea. In addition, it demonstrated the ability to predict this combination of events.

The fact that most of the students with dysmenorrhea belonged to the advanced semesters was determined as an influential variable for the definition of the degree of dysmenorrhea, given their possibility to acquire academic competences related to the management and modulation of pain during the training process as a doctor.

Around $60 \%$ of the eligible students voluntarily participated in an anonymous survey, with $<10$ items, which required $\sim 5$ minutes to completely fill out, fundamental characteristics in the creation of a survey; four of these items make up the WaLIDD score, a combination of manifestations, subjective (intensity, work ability), and objective (days of pain, location), frequent characteristics when dysmenorrhea manifests.

The use of the definition of dysmenorrhea was exhaustive and probably resulted in low frequency of the event, in comparison with investigations that included female university students from Bogotá and Medellín. These were monocentric, just like our research; however, it showed limited or uncalculated samples and their methodologies lacked a specific definition of dysmenorrhea, critical factors that affect the estimation, identification, and classification of this event. ${ }^{7-9}$

Previous investigations identified cases of dysmenorrhea by applying quantitative or multidimensional pain scales in an isolated manner, one of which was the VRS..$^{15,16,19}$

WaLIDD score showed a strong correlation with the subscales of VRS or with the sum of the scores obtained from its two items (pain and drug score). Both scales are multidimensional, but the WaLIDD score included the Wong-Baker Faces instrument (modified for this research), designed and validated to assess pain in the pediatric population, which has also proven to be useful in investigations involving adult populations with or without abdominal pain. ${ }^{20-22}$

The diagnosis of a condition formed by multiple criteria implies evaluation with an instrument that contains, among its items, the majority of these; besides the specific component to measure pain intensity, the WaLIDD score contained three frequently used criteria identified in the definitions of dysmenorrhea present in the literature: days of pain (D), work ability (Wa), and anatomical region of pain location (L).
Differential diagnosis for dysmenorrhea includes endometriosis, pelvic inflammatory disease, gynecological neoplasms, ectopic pregnancy, and other causes of chronic pelvic pain. ${ }^{1,3}$ Given the prognosis of these conditions, it was pertinent to design an instrument with high discriminatory power, which guides the physician with the highest precision and limits the traditional empirical approach. In women with dysmenorrhea or with physical inabilities due to dysmenorrhea, the WaLIDD score offers a very low rate of false negatives, together with a high AUC receiver operating characteristic and an adequate $\mathrm{LR}+$, properties that make it an excellent detection tool, preventing from clinical exclusion those women with a high probability of pathologies within the dysmenorrhea medical condition. ${ }^{23}$

An investigation that included medical students and evaluated dysmenorrhea with a rescaled numerical instrument showed excellent discriminatory properties to classify students in the three levels of the pain score component (VRS) which indicates pain. It is worth noting that it did not establish a case definition to identify students with dysmenorrhea and evaluated the operating capabilities of the VRS factor to discriminate students with or without dysmenorrhea. ${ }^{24}$

The ability to predict medical leave in students with dysmenorrhea is relevant, as there is evidence of the relationship between university absenteeism, caused by headache or dysmenorrhea, and poor academic performance..$^{25,26}$

Our study, despite being a preliminary validation, is the first to evaluate the operating capabilities of two multidimensional instruments designed to discriminate, in the general population, women with dysmenorrhea or medical leave secondary to dysmenorrhea. Among our limitations are the inclusion of participants from only one university and the use of a restrictive definition of dysmenorrhea, factors that could influence the low frequency of the condition, although it should be mentioned that the number of participants was twice the calculated sample. In specific variables, which are not part of the instruments, the effect size measured with the WaLIDD score was higher than that measured with the VRS subscales. These variables may correspond to characteristics of causal subgroups of dysmenorrhea that magnify pain. However, the size of the effect may be due to the lack of restriction with WaLIDD, which contains 13 levels, compared to the VRS's subscales, with four levels.

Further studies should focus on the process of external validation and assessment of the utility of the instrument in clinical settings such as the Emergency Department or 
Ambulatory Consultation, where some specific characteristics of PD or causes of secondary dysmenorrhea will be valuable, which will allow a better adjustment of this instrument, in order to identify specific pathological conditions.

We conclude that, by using this kind of scale (WaLIDD), we do not require paraclinical support and images, offering two important advantages: first, smaller delay time in application, compared to the time that we may require for paraclinical support or images for the study of the patient; and second, that the level of expertise for its application is not very demanding, does not require a gynecologist specialist for its application, which makes it very useful in triage services to be able to identify in an easier and faster way which patient has a high probability of having a dysmenorrhea-like pathology indicating its treatment, and which has a different probability and requires taking of images, paraclinical support, and assessment by a specialist, according to the differential diagnosis raised.

\section{Availability of data and materials}

The data sets generated and/or analyzed during the current study are available in the repository: http://www.juanncorpas. edu.co/investigacion/documentos-de-interes/.

\section{Acknowledgments}

Thanks are due to FUJNC and especially Dr Jaime García for allowing us to develop the present investigation within the School of Medicine; psychologist Yurley Campo Fontecha and OBGYN Henry Currea for their collaboration during the content validation phase of the questionnaire applied; and students Lilian Estupiñan, María Paula Bello, Angelica María Quintero, Natalia Pérez Malagón, and Jennifer Paola Martínez for helping us during the data collection phase.

\section{Author contributions}

AAT, LGP, FP, and MCMG drafted and contributed equally to the conception, design, study material collection, and systematization of information. AAT and MCM analyzed and interpreted the data. LGP, FP, VC, and MCB contributed to the instrument design and style correction. All authors contributed toward data analysis, drafting and critically revising the paper, gave final approval of the version to be published, and agree to be accountable for all aspects of the work.

\section{Disclosure}

The authors report no conflicts of interest in this work.

\section{References}

1. Osayande AS, Mehulic S. Diagnosis and initial management of dysmenorrhea. Am Fam Physician. 2014;89(5):341-346.

2. Yasir S, Kant B, Farooq M. Frequency of dysmenorrhea, its impact and management strategies adopted by medical students. J Ayub Med Coll Abbottabad. 2014;26(3):349-352.

3. Lefebvre G, Pinsonneault O, Antao V, et al. Primary dysmenorrhea consensus guideline. J Obstet Gynaecol Can. 2005;169:1117-1130.

4. Morrow C, Naumburg E. Dysmenorrhea. Prim Care. 2009;36:19-32.

5. Sahin S, Ozdemir K, Unsal A, Arslan R. Review of frequency of dysmenorrhea and some associated factors and evaluation of the relationship between dysmenorrhea and sleep quality in university students. Gynecol Obstet Invest. 2014;78(3):179-185.

6. Al-Jefout M, Seham A, Jameel H, et al. Dysmenorrhea: prevalence and impact on quality of life among young adult Jordanian females. J Pediatr Adolesc Gynecol. 2015;28:173-185.

7. Ju H, Jones M, Mishra G. The prevalence and risk factors of dysmenorrhea. Epidemiol Rev. 2014;36:104-113.

8. Yáñez N, Bautista-Roa SJ, Ruiz-Sternberg JE, Ruiz-Sternberg AM. Prevalencia y factores asociados a dismenorrea en estudiantes de ciencias de la salud. Rev Cienc Salud. 2010;8(3):37-48. Spanish.

9. Jiménez GA, González J, Ballesteros H, Miranda Y. Prevalencia, factores de riesgo y características clínicas de la dismenorrea en estudiantes de la facultad de Enfermería de la Universidad Pontificia Bolivariana. Medicina UPB. 2013;32(1):20-29. Spanish.

10. Monterrosa A. Dismenorrea primaria visión actual. Rev Colomb Ginecol Obstet. 2001;52:4. Spanish.

11. De Sanctis V, Soliman A, Bernasconi S, et al. Primary dysmenorrhea in adolescents: prevalence, impact and recent knowledge. Pediatr Endocrinol Rev. 2015;13(2):512-520.

12. Rodríguez AC, Gala S, Neves Â, et al. Dismenorreia em adolescentes e jovens adultas: prevalência, factores associados e limitações na vida diária [Dysmenorrhea in adolescents and young adults: prevalence, related factors and limitations in daily living]. Acta Med Port. 2011;24(2):383-388. Portuguese.

13. Singh A, Kiran D, Singh H, Nel B, Singh P, Tiwari P. Prevalence and severity of dysmenorrhea: a problem related to menstruation, among first and second year female medical students. Indian J Physiol Pharmacol. 2008;52(4):389-397.

14. Narring F, Yaron M, Ambresin AE. La dysménorrhée: un problème pour le pédiatre? [Dysmenorrhea: a problem for the pediatrician?]. Arch Pediatr. 2012;19(2):125-130. French.

15. Larroy C. Comparing visual-analog and numeric scales for assessing menstrual pain. Behav Med. 2002;27(4):179-181.

16. Chen CX, Kwekkeboom KL, Ward SE. Self-report pain and symptom measures for primary dysmenorrhea: a critical review. Eur J Pain. 2015; 19(3):377-391.

17. Harada T, Momoeda M, Terakawa N, Taketani Y, Hoshiai H. Evaluation of a low-dose oral contraceptive pill for primary dysmenorrhea: a placebocontrolled, double-blind, randomized trial. Fertil Steril. 2011;95(6): 1928-1931.

18. Andersch B, Milsom I. An epidemiologic study of young women with dysmenorrhea. Am J Obstet Gynecol. 1988;144(6):655-660.

19. Ortiz MI. Primary dysmenorrhea among Mexican university students: prevalence, impact and treatment. Eur J Obstet Gynecol Reprod Biol. 2010;152(1):73-77.

20. Garra G, Singer AJ, Taira BR, et al. Validation of the Wong-Baker FACES pain rating scale in pediatric emergency department patients. Acad Emerg Med. 2010;17(1):50-54.

21. Aziato L, Dedey F, Marfo K, Asamani JA, Clegg-Lamptey JN. Validation of three pain scales among adult postoperative patients in Ghana. BMC Nurs. 2015;14:42.

22. El-Sherbiny W, Saber W, Askalany AN, El-Daly A, Sleem AA. Effect of intra-abdominal instillation of lidocaine during minor laparoscopic procedures. Int J Gynaecol Obstet. 2009;106(3):213-215. 
23. Maxim LD, Niebo R, Utell MJ. Screening tests: a review with examples. Inhal Toxicol. 2014;26(13):811-828.

24. Kwuame EP, Mohammed BS. Menstrual pain assessment: comparing verbal rating scale (VRS) with numerical rating scales (NRS) as pain measurement tools. Int $J$ Womens Health Wellness. 2016;2(2): $1-5$.
25. Al-Kindi R, Al-Bulushi A. Prevalence and impact of dysmenorrhea among Omani high school students. Sultan Qaboos Univ Med J. 2011;11(4):485-491.

26. Souza-e-Silva HR, Rocha-Filho PA. Headaches and academic performance in university students: a cross-sectional study. Headache. 2011;51(10):1493-1502. 


\section{Supplementary materials}

Table SI Dysmenorrhea scales' effect sizes in relation to influential characteristics of pain measurement

\begin{tabular}{|c|c|c|c|}
\hline Variables & $\begin{array}{l}\text { Pain score } \\
\text { ES }(95 \% \mathrm{Cl})\end{array}$ & $\begin{array}{l}\text { Drug score } \\
\text { ES }(95 \% \mathrm{Cl})\end{array}$ & $\begin{array}{l}\text { WaLIDD } \\
\text { ES }(95 \% \mathrm{CI})\end{array}$ \\
\hline $\mathrm{D}$ & $0.346(0.274-0.4 I 7)$ & $0.465(0.388-0.542)$ & $0.732(0.570-0.894)$ \\
\hline$M L$ & $0.292(0.220-0.364)$ & $0.323(0.245-0.401)$ & $0.328(0.158-0.499)$ \\
\hline$D+M L$ & $0.699(0.627-0.77 I)$ & $0.86 I(0.783-0.940)$ & I.I54 (0.983-I.324) \\
\hline Days of blood flow $(>5)$ & $0.243(0.17 \mid-0.315)$ & $0.416(0.339-0.494)$ & $0.600(0.434-0.766)$ \\
\hline Intensity & 1.107 (1.04I-1.172) & $1.245(1.175-1.314)$ & $2.394(2.274-2.515)$ \\
\hline Location of pain $(>1)$ & $0.372(0.300-0.443)$ & $0.482(0.404-0.561)$ & $1.128(0.976-1.280)$ \\
\hline Days of pain $(>I)$ & $0.761(0.69 I-0.830)$ & $0.959(0.886-1.033)$ & I.65I (I.508-I.795) \\
\hline Treatment $(>I)$ & $0.389(0.318-0.460)$ & $0.610(0.535-0.686)$ & $0.569(0.404-0.735)$ \\
\hline
\end{tabular}

Notes: antensity $\geq$ "hurts little bit" according to the Wong-Baker scale. 'All combinations should include pain in the lower abdomen: lower abdominal plus lumbar, lower abdominal plus thighs, lower abdominal plus inguinal. Ninety-percent $\mathrm{Cls}$ were computed to allow comparison between scales. If the mean effect size of one group was not included within the $95 \% \mathrm{Cl}$ of the other group, then the two groups differed significantly at $p<0.05$.

Abbreviations: WaLIDD, working ability, location, intensity, days of pain, dysmenorrhea; ES, effect size; ML, medical leave; D, dysmenorrhea.

Table S2 Baseline characteristics of university students related to medical leave

\begin{tabular}{|c|c|c|c|c|}
\hline Characteristic & $\begin{array}{l}\text { Medical leave } \\
n=140(23.9 \%)\end{array}$ & $\begin{array}{l}\text { Nonmedical leave } \\
n=445(76.1 \%)\end{array}$ & $\begin{array}{l}\text { Total } \\
\mathrm{N}=585\end{array}$ & $p$-value \\
\hline Age, ${ }^{a}$ mean $\pm S D$ & $21 \pm 1.9$ & $2 \mathrm{I} \pm 2.2$ & $2 I \pm 2.1$ & 0.925 \\
\hline Menarche, ${ }^{a}$ mean $\pm S D$ & $12.5 \pm 1.5$ & $12.3 \pm 1.6$ & $12.3 \pm 1.5$ & 0.088 \\
\hline Menarche before 12 years, $\mathrm{n}(\%)$ & $35(25)$ & $123(27.6)$ & $158(27)$ & 0.539 \\
\hline \multicolumn{5}{|l|}{ Menstrual cycles, $n(\%)$} \\
\hline$<2$ I days & $15(10.7)$ & $35(7.9)$ & $50(8.5)$ & 0.379 \\
\hline $28-30$ days & $106(75.7)$ & $336(75.5)$ & $442(75.5)$ & 0.950 \\
\hline$>35$ days & $12(8.8)$ & $36(8.1)$ & $48(8.2)$ & 0.996 \\
\hline Other & $7(5)$ & $38(8.5)$ & $45(7.6)$ & 0.234 \\
\hline Days of menstrual blood flow, ${ }^{a}$ mean $\pm S D$ & $5.2 \pm 2.1$ & $4.9 \pm 1.7$ & $4.9 \pm 1.8$ & 0.057 \\
\hline
\end{tabular}

Notes: alt was a rejected normal distribution in quantitative variables (Shapiro-Wilk's test) and used a non-paired $t$-test for comparison between groups. All students with or without medical leave was used as the denominator to calculate the proportion of students with a specific characteristic.

Table S3 Correlation between dysmenorrhea and other features

\begin{tabular}{|c|c|c|c|c|}
\hline \multirow[t]{2}{*}{ Features } & \multirow[t]{2}{*}{ WaLIDD score } & \multicolumn{3}{|c|}{ Verbal rating score } \\
\hline & & Pain & Drug & Pain/drug \\
\hline \multirow[t]{2}{*}{ Pain score ${ }^{a}$} & 0.833 & & & \\
\hline & 0.000 & & & \\
\hline \multirow[t]{2}{*}{ Drug score ${ }^{a}$} & 0.736 & 0.402 & & \\
\hline & 0.000 & 0.000 & & \\
\hline \multirow[t]{2}{*}{ Pain/drug score ${ }^{b}$} & 0.840 & 0.709 & 0.418 & \\
\hline & 0.000 & 0.000 & 0.000 & \\
\hline \multirow[t]{2}{*}{ Age } & -0.050 & -0.066 & -0.010 & -0.087 \\
\hline & 0.223 & 0.111 & 0.809 & 0.036 \\
\hline \multirow[t]{2}{*}{ Menarche } & -0.066 & -0.058 & -0.062 & -0.068 \\
\hline & 0.112 & 0.158 & 0.135 & 0.100 \\
\hline \multirow[t]{2}{*}{ Duration of menstrual blood flow ${ }^{c}$} & 0.175 & 0.119 & 0.193 & 0.089 \\
\hline & 0.000 & 0.004 & 0.000 & 0.031 \\
\hline \multirow[t]{2}{*}{ Therapy tried } & 0.462 & 0.147 & 0.228 & 0.794 \\
\hline & 0.000 & 0.000 & 0.000 & 0.000 \\
\hline \multirow[t]{2}{*}{ Incapabilityc } & 0.029 & 0.114 & 0.121 & -0.380 \\
\hline & 0.489 & 0.006 & 0.003 & 0.000 \\
\hline
\end{tabular}

Notes: alt is a feature of the verbal rating score. ${ }^{\mathrm{l} l t}$ is a sum of two features of the verbal rating score. ${ }^{\mathrm{C}}$ The measurement was made in days. The upper line in each entry corresponds to the Spearman-Rho value and the lower line denotes the probability value, $p$. Significant $p<0.003$ values are shown in bold.

Abbreviation: WaLIDD, working ability, location, intensity, days of pain, dysmenorrhea. 
Table S4 Risk of incapability in relation to features of scores

\begin{tabular}{|c|c|c|c|}
\hline Features & $\begin{array}{l}\text { Incapability } \\
n=\mid 40 \text { (23.9\%) }\end{array}$ & $\begin{array}{l}\text { Non-incapability } \\
n=445 \text { (76.1\%) }\end{array}$ & OR (95\% Cl) \\
\hline \multicolumn{4}{|l|}{ WaLIDD score } \\
\hline \multicolumn{4}{|l|}{ Location, n (\%) } \\
\hline Lower abdominal & I $23(87.8)$ & $37 I$ (83.3) & I.44 (0.83-2.60) \\
\hline Lumbar & $48(34.2)$ & $155(34.8)$ & $0.97(0.65-1.45)$ \\
\hline Thighs & $24(17.1)$ & $57(12.5)$ & I.4I (0.84-2.37) \\
\hline Inguinal & $14(10)$ & $33(7.2)$ & $1.39(0.72-2.68)$ \\
\hline \multicolumn{4}{|l|}{ Wong-Baker, n (\%) } \\
\hline 0 & II (7.8) & $34(7.4)$ & $1.03(0.5 \mathrm{I}-2.10)$ \\
\hline 1 & $15(10.7)$ & $80(19.1)$ & $0.55(0.30-0.98)$ \\
\hline 2 & $50(35.7)$ & $186(4 \mid .7)$ & $0.77(0.52-1.14)$ \\
\hline 3 & $64(45.7)$ & $145(32.5)$ & $1.74(1.18-2.56)$ \\
\hline \multicolumn{4}{|l|}{ Days of pain, $n(\%)$} \\
\hline 0 & $10(7.1)$ & $40(8.9)$ & $0.78(0.38-1.60)$ \\
\hline 1 & $95(67.8)$ & $322(72.3)$ & $0.80(0.53-\mid .2 I)$ \\
\hline 2 & $27(19.2)$ & $73(16.4)$ & $1.22(0.74-1.98)$ \\
\hline 3 & $8(5.7)$ & $10(2.2)$ & $2.63(1.02-6.8 I)$ \\
\hline \multicolumn{4}{|l|}{ Working ability, n (\%) } \\
\hline 0 & $38(27.1)$ & $139(31.2)$ & $0.82(0.53-1.25)$ \\
\hline 1 & $66(47.1)$ & $224(49.2)$ & $0.87(0.60-1.28)$ \\
\hline 2 & $36(25.7)$ & $72(16.1)$ & $1.79(1.13-2.82)$ \\
\hline 3 & $10(7.1)$ & $10(2.2)$ & $3.34(1.36-8.21)$ \\
\hline \multicolumn{4}{|l|}{ Verbal rating score } \\
\hline \multicolumn{4}{|l|}{ Pain score, n (\%) } \\
\hline 0 & $25(17.8)$ & 147 (33) & $0.44(0.27-0.70)$ \\
\hline 1 & $28(20)$ & $67(15)$ & I $3.67(8.23-22.68)$ \\
\hline 2 & $85(60.7)$ & $227(5 \mathrm{I})$ & $1.48(1.00-2.18)$ \\
\hline 3 & $2(1.4)$ & $4(0.9)$ & $1.59(0.28-8.81)$ \\
\hline \multicolumn{4}{|l|}{ Drug score, n (\%) } \\
\hline 0 & $32(29.1)$ & $145(81.92)$ & $0.61(0.39-0.95)$ \\
\hline 1 & $42(30)$ & $142(77.17)$ & $0.91(0.60-1.38)$ \\
\hline 2 & $42(30)$ & $125(74.85)$ & I.09 (0.72-I.76) \\
\hline 3 & $24(17.1)$ & $33(57.89)$ & $2.58(1.46-4.54)$ \\
\hline
\end{tabular}

Notes: Risk of incapability in relation with features of verbal rating score and features of WaLIDD was calculated with value of OR with $95 \% \mathrm{Cl}$. For this, we used OpenEpi program in line. Numbers in bold are variables that were included in the model to predict dysmenorrhea.

Abbreviation: WaLIDD, working ability, location, intensity, days of pain, dysmenorrhea.

\section{Publish your work in this journal}

The International Journal of Women's Health is an international, peerreviewed open-access journal publishing original research, reports, editorials, reviews and commentaries on all aspects of women's healthcare including gynecology, obstetrics, and breast cancer. The manuscript management system is completely online and includes

\section{Dovepress}

a very quick and fair peer-review system, which is all easy to use. Visit http://www.dovepress.com/testimonials.php to read real quotes from published authors. 